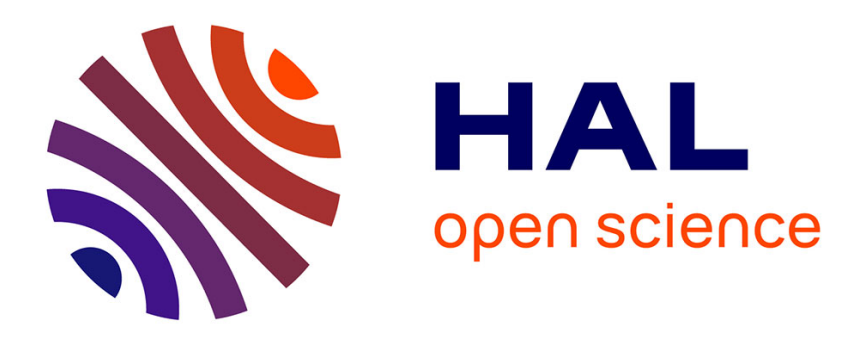

\title{
The H-microdirectional model: accounting for a mesoscopic scale
}

\author{
François Nicot, F. Darve
}

\section{To cite this version:}

François Nicot, F. Darve. The H-microdirectional model: accounting for a mesoscopic scale. Mechanics of Materials, 2011, 43 (12), pp.918-929. 10.1016/j.mechmat.2011.07.006 . hal-00622492

\section{HAL Id: hal-00622492 \\ https://hal.science/hal-00622492}

Submitted on 12 Sep 2011

HAL is a multi-disciplinary open access archive for the deposit and dissemination of scientific research documents, whether they are published or not. The documents may come from teaching and research institutions in France or abroad, or from public or private research centers.
L'archive ouverte pluridisciplinaire HAL, est destinée au dépôt et à la diffusion de documents scientifiques de niveau recherche, publiés ou non, émanant des établissements d'enseignement et de recherche français ou étrangers, des laboratoires publics ou privés. 


\section{Accepted Manuscript}

The $H$-microdirectional model: accounting for a mesoscopic scale

François Nicot, Félix Darve

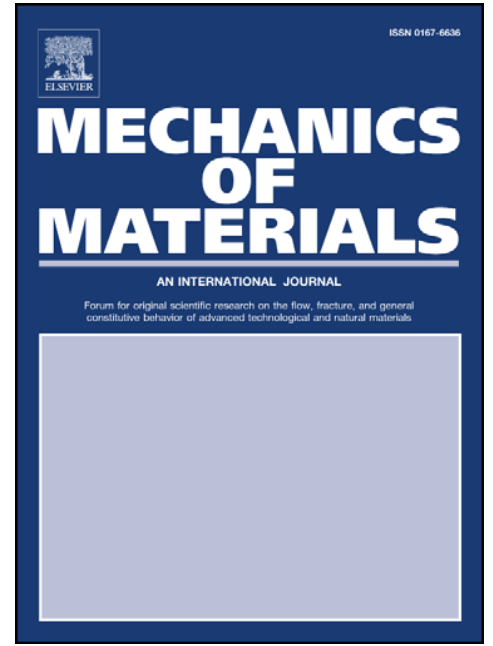

PII:

S0167-6636(11)00123-2

DOI:

10.1016/j.mechmat.2011.07.006

Reference:

MECMAT 1893

To appear in:

Mechanics of Materials

Received Date:

30 June 2010

Revised Date:

6 July 2011

Please cite this article as: Nicot, F., Darve, F., The $H$-microdirectional model: accounting for a mesoscopic scale, Mechanics of Materials (2011), doi: 10.1016/j.mechmat.2011.07.006

This is a PDF file of an unedited manuscript that has been accepted for publication. As a service to our customers we are providing this early version of the manuscript. The manuscript will undergo copyediting, typesetting, and review of the resulting proof before it is published in its final form. Please note that during the production process errors may be discovered which could affect the content, and all legal disclaimers that apply to the journal pertain. 


\title{
The $\boldsymbol{H}$-microdirectional model: accounting for a mesoscopic scale
}

\author{
François NICOT $^{1}$ and Félix DARVE ${ }^{2}$ \\ (1) Cemagref, Geomechanics Group, ETNA, Grenoble (France) \\ (2) Laboratoire Sols Solides Structures Risques, UJF-INPG-CNRS, Grenoble (France) \\ Corresponding author: francois.nicot@ cemagref.fr
}

\begin{abstract}
:
Solving boundary value problems requires implementation of sufficiently robust constitutive models. Most models try to incorporate a great deal of phenomenological ingredients, but this refining often leads to overcomplicated formulations, requiring a large number of parameters to be identified. A powerful alternative can be found with micromechanical models, where the medium is described as a distribution of elementary sets of grains. The complexity is not related to the constitutive description, but to the multiplicity of contacts oriented along all the directions of the physical space. This paper proposes an advanced micromechanical model that introduces an intermediate scale (mesoscopic scale): elementary hexagonal patterns of adjoining particles. This is advantageous with respect to current micromechanical models that generally describe the material through a single distribution of contacts. This new approach makes it possible to take many constitutive properties into account in a very natural way, such as the occurrence of diffuse failure modes. These preliminary results are presented in order to give clear insights into the capability of such multiscale approaches.
\end{abstract}

\section{KEYWORDS:}

Granular material, Homogenization, Multiscale approach, Microstructure, Mesoscopic scale, Force chains. 


\section{INTRODUCTION}

There has been renewed interest in granular materials in the last few years in the physics, materials engineering, and soil mechanics communities. Granular materials are involved in a variety of engineering purposes, including among others pharmaceutical engineering, food particle storage, and civil engineering. As highlighted by Tordesillas (2007) and Tordesillas and Muthuswamy (2009), granular materials exhibit a wide spectrum of emergent features that are currently being intensively investigated: the incrementally nonlinear character of the constitutive response, the nonassociated character of plastic strains, the existence of a flow rule that can be regular or irregular (Nicot and Darve, 2007a and 2007b; Darve and Nicot, 2005a and 2005b), and the existence of a bifurcation domain, within the plastic limit surface, in which a variety of failure modes can be encountered (Darve et al., 2004; Nicot et al., 2009).

Developing constitutive relations that succeed in recovering these features is a major challenge. The last few decades have seen the development of a large number of phenomenological models. Such models are developed in a proper, enriched mathematical framework to formulate the different observed phenomena, for example, elastoplastic theories (see for example Taylor, 1934 and 1938; Drucker and Prager, 1952; Hill, 1967; Rice, 1970 and 1975), generalized plasticity (Zienkiewicz and Mroz, 1984; Pastor, 1990), endochronic models (Bazant, 1978), hypoplastic theories (Kolymbas, 1991 and 1999), and incrementally nonlinear models (Darve, 1990 and 1995). As an alternative, multiscale approaches consider that the variety of constitutive properties stem essentially from the granular character (NematNasser and Mehrabadi, 1984; Nemat-Nasser, 2000), exhibiting geometrical aspects such as contact opening or closure, contact sliding, existence of force chains that may buckle (Horne, 1965; Drescher and de Josselin de Jong, 1972; Radjai et al., 1999; Tordesillas and Muthuswamy, 2009), and development of intermediate clusters (Walker and Tordesillas, 2010, Tordesillas et al., 2010). The local behavior on the contact scale can usually be simulated in a very straightforward manner by elastic-plastic laws to address the overall behavior of the assembly. The complexity of the constitutive behavior of granular assemblies does not stem only from the local properties, but also from disordered packing.

The derivation of a constitutive relation under a closed form requires relations bridging the different scales: relations between overall stress or strain tensor and a correspondent local (static or kinematic) variable. If the contact forces can be chosen as a convenient local static variable, the question of the relevant local kinematic variable is more crucial. Usually, the 
relative displacement between adjoining particles is employed. However, the derivation of the relative displacement from the macroscopic strain is not well established. It is now recognized that the relative displacement of any contact is not proportional to the macroscopic strain (Cambou et al., 2000; Agnolin and Kruyt, 2008; Agnolin and Roux, 2008). In fact, the relative displacement field consists of two parts: an average part corresponding to a uniform field directed by the applied boundary conditions and a fluctuation term stemming from the local packing around the contact considered (Kruyt and Rothenburg, 2002).

In this paper, the microdirectional model is first reviewed. This model, initially developed to describe the mechanical behavior of snow (Nicot, 2003 and 2004), was extended to any granular material (Nicot and Darve, 2005). However, the affine kinematic assumption used omits any fluctuation of the local kinematic field with respect to the overall strain. In spite of the model's rather good ability to reproduce most of the constitutive features of the granular materials, some discrepancies remain. Going further requires a more accurate description of the kinematics involved. Therefore, in the continuity of the microdirectional model, the $\mathrm{H}$ microdirectional model recently developed is presented here. We show how incorporating an (hexagonal) intermediate scale is advantageous. The model is presented in a two-dimensional context; then a series of simulations along standard loading paths gives an account of the capability of this new constitutive formulation.

Time and spatial differentials of any variable $\psi$ will be distinguished by denoting $\delta \psi$ the time differential of $\psi$ (defined as the product of the particulate derivative $\dot{\psi}$ by the infinitesimal time increment $\delta t$ ) with respect to a given frame, and by denoting $d \psi$ the spatial differential of $\psi$. 


\section{A BRIEF REVIEW OF THE MICRODIRECTIONAL MODEL}

\subsection{The homogenization scheme}

The microdirectional model was initially developed to describe the mechanical behavior of snow (Nicot, 2003). The model was then generalized to any type of granular assembly, with a particular emphasis on frictional granular materials (Nicot and Darve, 2005).

Basically, the application of an incremental loading to the boundary grains of a granular assembly (regarded as a material point) directs a mechanical imbalance for those grains between external forces and internal forces resulting from the contact with the other grains. According to Newton's second law, this mechanical imbalance induces the displacement of boundary particles, thereby modifying the contact forces. Thus, the external loading progressively disturbs the whole assembly that is rearranged, according to Newton's second law, to reach a new equilibrium configuration. As a consequence, the mechanical response of a granular assembly results from dynamical mechanisms governing the motion of each particle constrained by the existence of adjoining particles. This is exactly the leading principle of discrete element models (Cundall, 1992). However, the number of degrees of freedom of the nonlinear differential equation system makes an analytical relation impossible between incremental strain and stress.

Setting up a constitutive relation, therefore, requires the introduction of additional assumptions so as to avoid solving the balance equations of each particle. In the microdirectional model, the granular assembly is described as a distribution of contacts oriented along each direction of the physical space. All contact directions are independent of each other. The relative displacement of pairs of granules associated with each contact does not derive from the resolution of balance equations, but stems from an affine expression involving the macroscopic strain. More specifically, the microdirectional model relates the Cauchy stress tensor $\delta \overline{\bar{\sigma}}$ to the strain tensor $\delta \overline{\bar{\varepsilon}}$ by taking the local behavior on the contact scale into account. The reverse scheme can also be considered: starting from a given stress

tensor $\delta \overline{\bar{\sigma}}$, the small strain tensor $\delta \overline{\bar{\varepsilon}}$ is deduced (Cambou et al., 1995; Chang and Hicher, 2005). Fundamentally, the microdirectional model is based on a homogenization/localization procedure that can be resolved in three stages (Fig. 1). These stages are very briefly reviewed here (for more details, see Nicot and Darve, 2005).

The stress averaging corresponds to the Love formula (Love, 1927; Christoffersen et al., 1981; Mehrabadi et al., 1982): 
$\sigma_{i j}=\frac{1}{V} \sum_{c=1}^{N_{c}} F_{i}^{c} l_{j}^{c}$

where $\overrightarrow{l^{c}}$ is the branch vector joining the centers of particles in contact on contact $c, \overrightarrow{F^{c}}$ is the contact force, and the sum is extended to all the $N_{c}$ contacts occurring in the RVE of volume $V$. The norm of the branch vector $\overrightarrow{l^{c}}$ is assumed to be a constant parameter (equal to the mean diameter of the grains) whose evolution over loading programs is ignored. This ensures that the terms $\overrightarrow{F^{c}}$ and $\overrightarrow{l^{c}}$ are uncorrelated. The discrete summation given in Eq. (1) can be replaced with a continuous integration over all the contact directions in the physical space. This scheme confers the directional character to the model:

$\sigma_{i j}=2 r_{g} \iint_{D} \hat{F}_{i} n_{j} \omega d \Omega$

where $\omega$ is the density of contacts along each space direction $\vec{n}, r_{g}$ denotes the mean radius of the sphere-shaped grains, $\hat{\vec{F}}$ is the average of all contact forces $\overrightarrow{F^{c}}$ associated with contacts oriented in the direction $\vec{n}, d \Omega$ is the elementary solid angle, and the integration surface $D$ is the half sphere. After differentiation it follows that:

$\delta \sigma_{i j}=2 r_{g} \iint_{D} \delta \hat{F}_{i} n_{j} \omega d \Omega+2 r_{g} \iint_{D} \hat{F}_{i} n_{j} \delta \omega d \Omega$

The kinematic localization is given by:

$\delta \hat{u}_{i}(\vec{n})=2 r_{g} \delta \varepsilon_{i j} n_{j}$

where $\hat{\vec{u}}(\vec{n})$ is the kinematic variable linked to $\hat{\vec{F}}(\vec{n})$ along the contact direction $\vec{n}$. As $\hat{\vec{u}}(\vec{n})$ depends only on the direction $\vec{n}$, this term is also denoted as the directional kinematic variable.

The local behavior is described properly using, for example, an elastic-plastic mechanical model relating both the local normal force $F_{n}^{c}$ and the local tangential force $F_{t}^{c}$ to both the local normal relative displacement $u_{n}^{c}$ and the local tangential relative displacement $u_{t}^{c}$. This model includes a Mohr-Coulomb criterion and can be expressed under the following 
incremental formalism, which introduces a normal elastic stiffness $k_{n}$ and a tangential elastic stiffness $k_{t}$, both constant, and a local friction angle $\varphi_{g}$ :

$\delta F_{n}^{c}=k_{n} \delta u_{n}^{c}$

$\delta \vec{F}_{t}^{c}=\min \left\{\left\|\vec{F}_{t}^{c}+k_{t} \delta \vec{u}_{t}^{c}\right\|, \tan \varphi_{g}\left(F_{n}^{c}+k_{n} \delta u_{n}^{c}\right)\right\} \frac{\vec{F}_{t}^{c}+k_{t} \delta \vec{u}_{t}^{c}}{\left\|\vec{F}_{t}^{c}+k_{t} \delta \vec{u}_{t}^{c}\right\|}-\vec{F}_{t}^{c}$

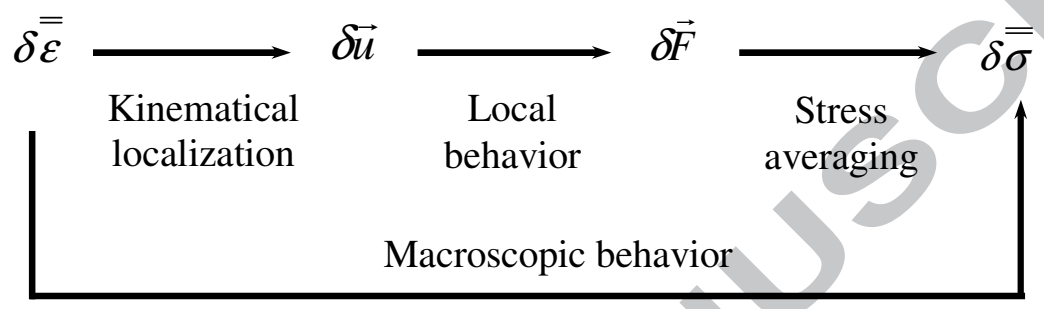

Fig. 1. General homogenization scheme relating both incremental stress and strain tensors.

The change in the fabric of the granular assembly is modeled by the increase or the decrease in the number of contacts along each direction of the physical space. In this approach, the number of contacts along a given direction is related to the normal strain rate $\delta \varepsilon_{i j} n_{i} n_{j}$ along this direction. Following pioneering work based on physical evidence (Oda, 1972), it is thought that the number of contacts increases along contractive directions, whereas it decreases along dilative directions. Therefore, the distribution of contacts is likely to evolve over a loading path, inducing anisotropy to the texture (see Nicot and Darve, 2005, for more details).

\subsection{Limitations of the microdirectional model}

Basically, the main limitation of the microdirectional model lies in the kinematic assumption given in Eq. (4). This assumption means that the local deformation at the contact zone corresponds to the mean incremental strain tensor acting within the specimen. This is not exact, as can be observed from the following analysis. Considering a granular specimen, subjected, for example, to a drained triaxial loading, a pair of adjoining granules in contact 
oriented along the axial direction (corresponding to the major principal strain/stress direction) is the subject of matter (Fig. 2).

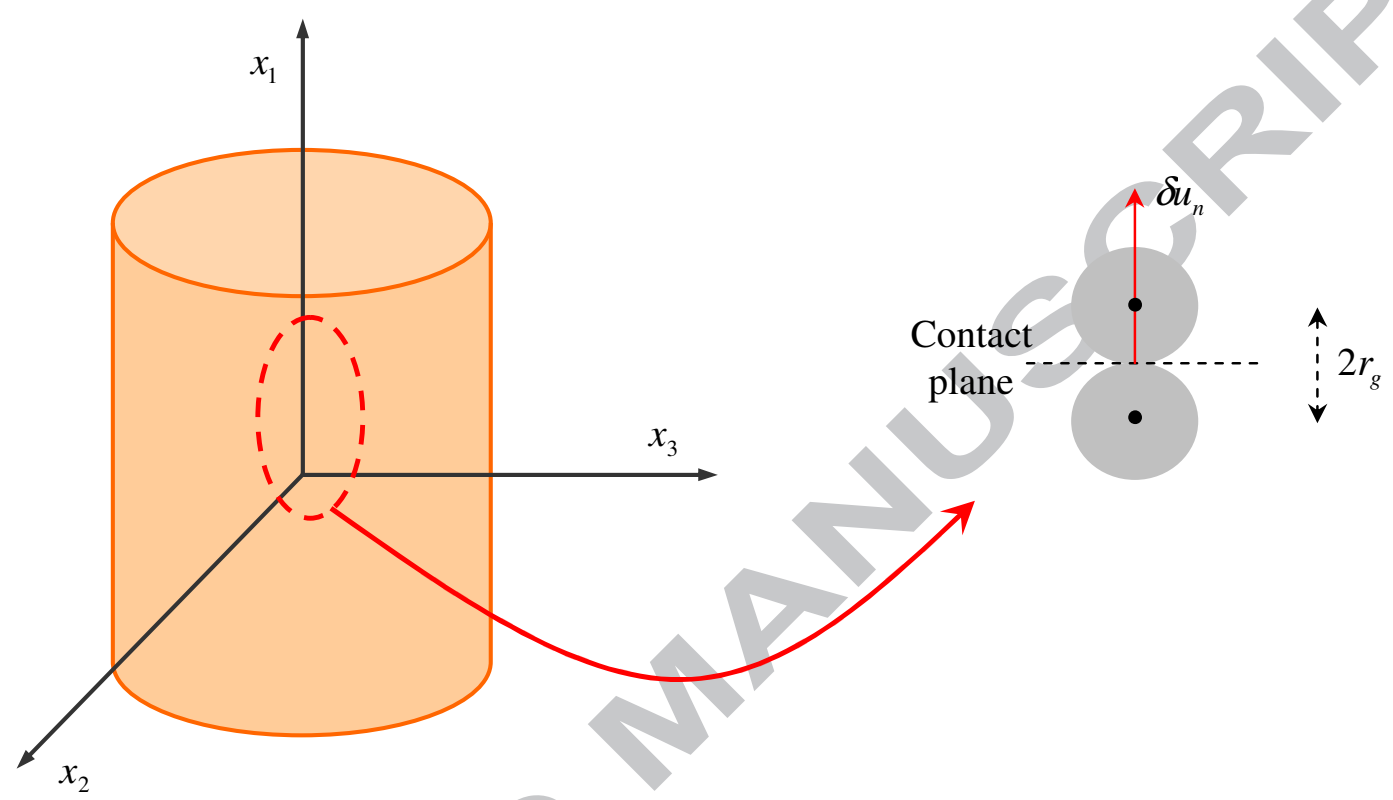

Fig. 2. Axisymmetric drained triaxial loading path. Grains in contact along the major principal direction.

In axisymmetric conditions, and according to Eq. (4), the relative displacements $\delta u_{n}$ and $\delta u_{t}$ along the normal direction $\vec{n}=\vec{x}_{1}$ to the idealized contact plane and along the tangential direction $\vec{t} \in\left(\vec{x}_{2}, \vec{x}_{3}\right)$ are given by:

$$
\begin{aligned}
& \delta u_{n}=2 r_{g} \delta \varepsilon_{i j} n_{i} n_{j}=2 r_{g} \delta \varepsilon_{11} \\
& \delta u_{t}=2 r_{g} \delta \varepsilon_{i j} n_{i} t_{j}=0
\end{aligned}
$$

For a triaxial loading in compression, $\delta u_{n}$ is always positive, whereas $\delta u_{t}$ is nil. Thus, along that direction, contacts always behave elastically. Neither opening nor sliding mechanisms occur. As a consequence, the stiffness of the specimen is maximal along this direction and is proportional to normal elastic stiffness $k_{n}$ of grains:

$\delta F_{n}=2 r_{g} k_{n} \delta \varepsilon_{11}$ 
In fact, granular assemblies essentially deform due to grain rearrangement by sliding, rolling, and contact opening. The overall deformation of most granular assemblies (involving sufficiently rigid grains) does not stem from the deformation of grains in contact. Deformation of grains in contact is mobilized when the grains can no longer rearrange. This is the case, for example, for oedometric loading paths (lateral strains are prevented, whereas an axial loading rate in imposed). Axial stiffness dramatically increases when the void ratio decreases, resulting from multiple direct grain-to-grain compressions.

As a consequence, with no additional ingredient, the microdirectional model cannot correctly simulate the mechanical response of a granular specimen along a drained triaxial loading path. To do so, an adaptation was incorporated, by removing all contacts oriented along directions within a (so-called extinction) cone. This cone is centered on the major principal strain direction, the angular amplitude, $\theta_{e}$ of which is a free parameter.

Indeed, this method was shown to be powerful, allowing realistic simulation of most of the standard loading paths. For example, the results provided by the microdirectional model along an undrained triaxial loading path (the volume of the sample is assigned to remain constant, while a constant axial strain rate is imposed) are qualitatively satisfying. As reported abundantly in the literature (Castro, 1969; Lade and Pradel, 1990; Lade, 1992; Chu et al., 2003), the response of the specimen closely depends on its initial void ratio. In axisymmetric conditions, for loose specimens, the curve giving the evolution of the deviatoric stress $q=\sigma_{1}-\sigma_{3}$ in terms of the mean effective pressure $p^{\prime}=\frac{1}{3}\left(\sigma_{1}+2 \sigma_{3}\right)$ passes through a peak, then follows a descending branch leading progressively toward the complete vanishing of stresses. This is the liquefaction phenomenon. For dense specimens, no liquefaction is observed, and stresses increase until the Mohr-Coulomb limit is reached. When simulated by using the microdirectional model, the same results are qualitatively obtained, as a function of the angular amplitude $\theta_{e}$. For large values of $\theta_{e}$ (typically, 30 degrees), the response simulated corresponds to that of a loose specimen. Conversely, for small values of $\theta_{e}$, the behavior of dense specimens is retrieved. Thus, the extinction cone plays a role very similar to the density of the medium. This feature was investigated, and was related to the notion of force chains buckling (see Nicot and Darve, 2007b, for more details).

\subsection{Efficiency of the extinction cone principle}


The value of the extinction cone principle can be appreciated from the comparison between simulated and experimental results obtained along drained triaxial tests run with sand specimens. Experimental tests were conducted with monodisperse sand $\left(d_{50}=0.6 \mathrm{~mm}\right)$ called Ticino sand, well characterized from a geotechnical point of view and adopted in many studies (Valentino et al., 2008).

First, a calibration stage was run, along a drained triaxial path (in axisymmetric conditions), after an initial isotropic compression until a confining pressure of $109 \mathrm{kPa}$. This stage included an unloading/reloading path, at a deviatoric stress equal to $200 \mathrm{kPa}$. This loading path was simulated by using the parameters reported in Table 1, providing quite good agreement between experimental and numerical results.

\begin{tabular}{c|c|c|c|c|}
$\begin{array}{c}\text { Initial isotropic } \\
\text { stress }(\mathrm{kPa})\end{array}$ & $\theta_{e}(\mathrm{deg})$ & $k_{n}(\mathrm{kN} / \mathrm{m})$ & $k_{t}(\mathrm{kN} / \mathrm{m})$ & $\varphi_{g}(\mathrm{deg})$ \\
\hline 109 & 32 & 26,000 & 11,000 & 10
\end{tabular}

Table 1. Numerical simulation: constitutive parameters and initial conditions.

The evolution of the deviatoric stress against the axial strain is given in Fig. 3. The comparison between both experimental and numerical curves is quite satisfying. In particular, the hardening regime leading to a decrease in the tangent stiffness modulus is correctly reproduced. As seen in Fig. 4, the volumetric behavior is less accurately reproduced. The initial elastic contractancy together with the residual dilatancy angle are overestimated by the simulation. However, on the whole, the main qualitative constitutive features are suitably reproduced, displaying a typical volumetric behavior for dense granular materials. 


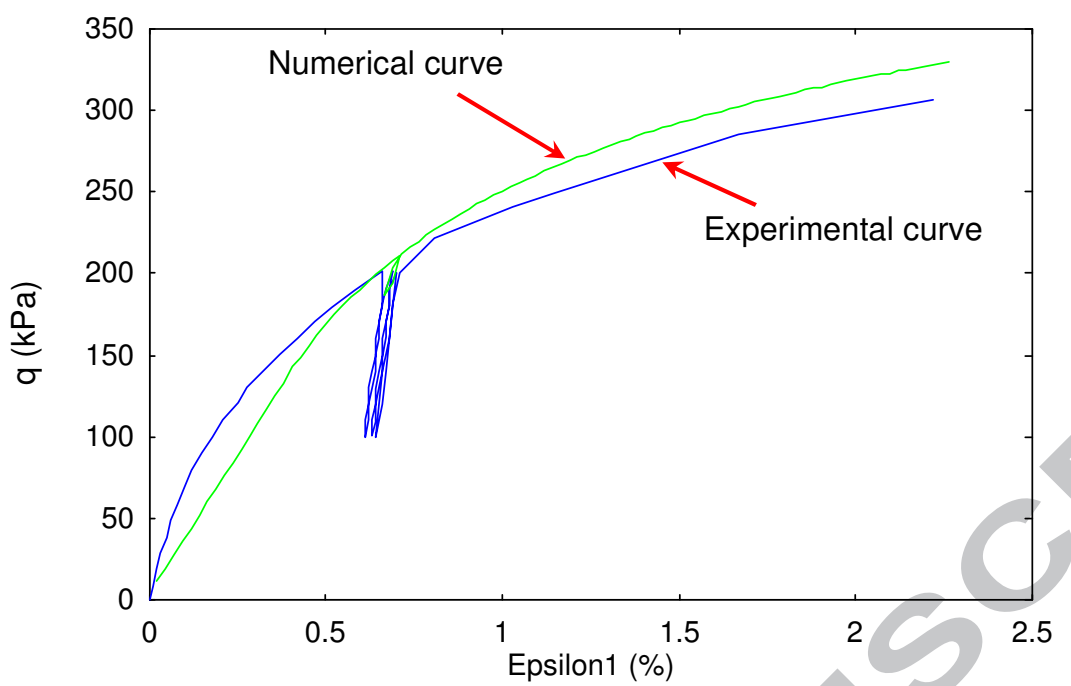

Fig. 3. Calibration phase along an axisymmetric drained triaxial loading path, including an unloading/reloading stage. Evolution of deviatoric stress.

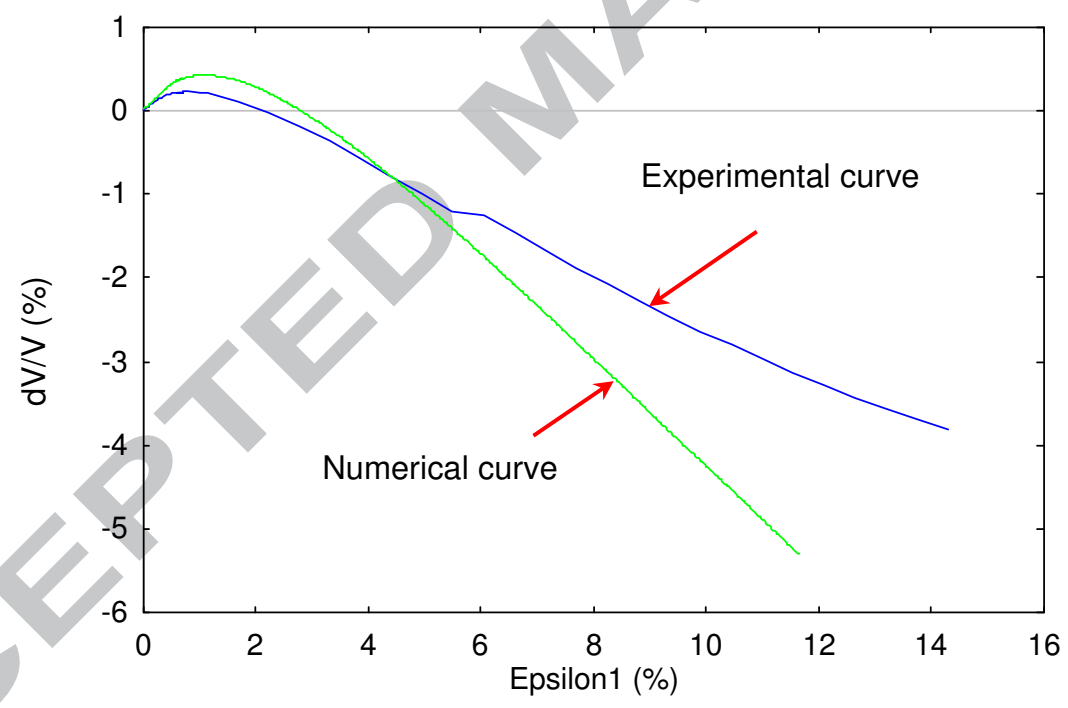

Fig. 4. Calibration phase along an axisymmetric drained triaxial loading path, including an unloading/reloading stage. Evolution of volumetric strain.

Then a validation stage was carried out, along drained triaxial loading paths, at different initial confining pressures (200 and $300 \mathrm{kPa}$ ). Experimental tests were conducted with the same Ticino sand, by using the same initial void ratio (the initial relative density was equal to $45 \%$ ). These tests were simulated with the microdirectional model using the numerical parameters identified during the calibration stage (Table 1). The comparison between 
experimental and numerical results is given in Fig. 5, where the deviatoric stress is plotted against the axial strain. The main tendencies are reproduced. In particular, the increase in the plastic limit with the confining pressure is correctly simulated. For the two confining pressures experienced, the agreement between the experimental and numerical curves is quite satisfying over the small axial strain domain (up to 7-8\%). Beyond, a significant discrepancy is observed. In fact, experimental curves pass through a peak, followed by a softening regime. This softening regime is often attributed to a structural effect, associated with localized deformation. As the problem is considered homogeneous (continuum material point), the constitutive model cannot reproduce this softening, leading to the divergence between both the monotonic increasing numerical branch and the descending (post-peak regime) experimental branch.

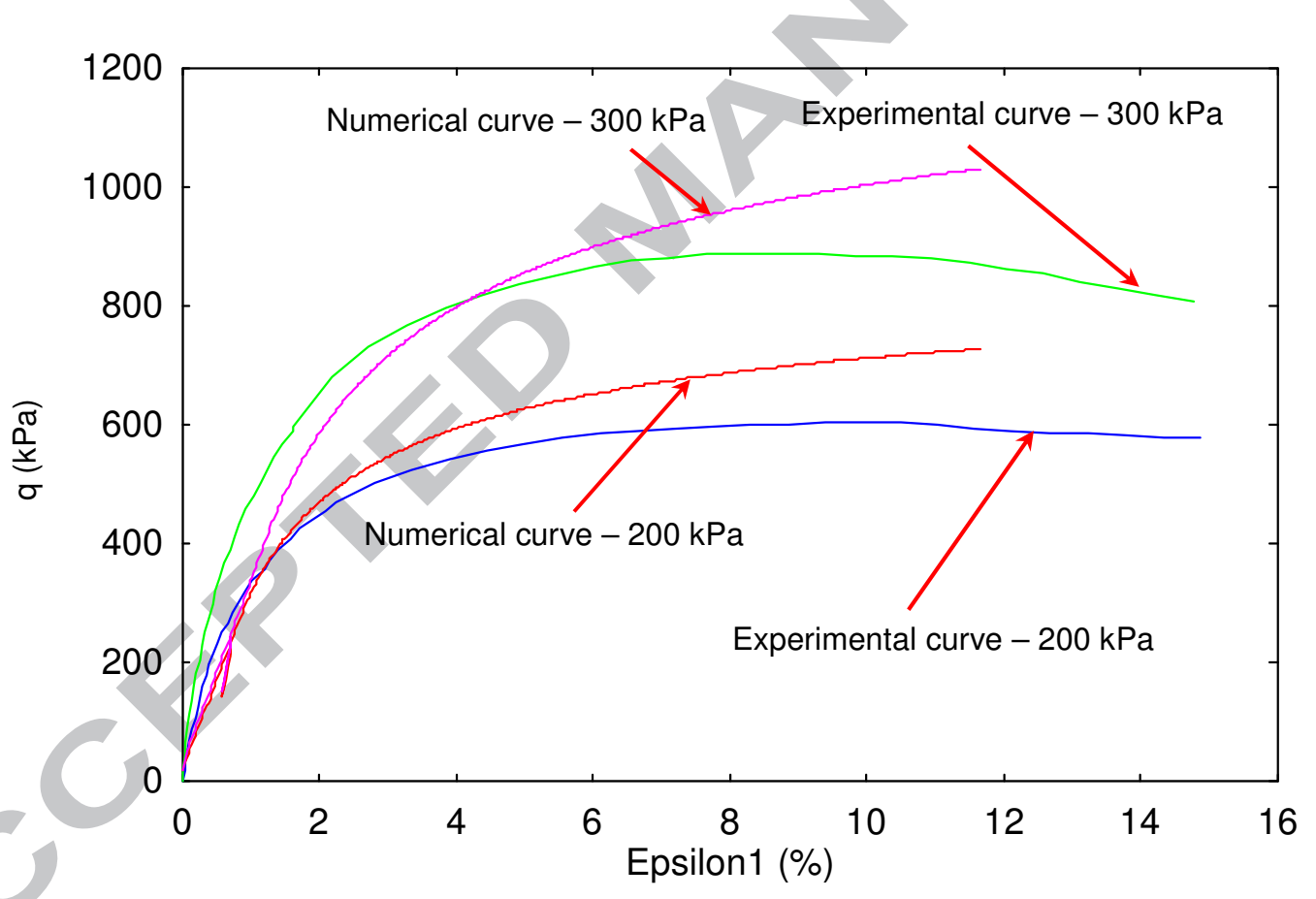

Fig. 5. Validation stage along an axisymmetric drained triaxial loading path, at different initial confining stresses. Evolution of deviatoric stress.

In spite of this disagreement, the capability of the microdirectional model for qualitatively simulating some of the constitutive features of granular materials should be noted (see also Nicot and Darve, 2005, 2006 and 2007b; Darve and Nicot, 2005b and 2005c for a complete 
review). These results suggest that the principle of this type of approach, based on a homogenization scheme including a directional character, is relevant. Going further requires a more advanced description of the kinematics involved, to overcome the strong assumption associated with Eq. (4). A feasible way would be to implement an intermediate scale within the microdirectional model. A spatial distribution of hexagonal sets of grains is incorporated, leading to the development of the $H$-microdirectional model, presented in the next section. 


\section{ACCOUNTING FOR A MESOSCOPIC SCALE}

\subsection{The constitutive relation}

The main weakness of the microdirectional model is related to the kinematic description (Eq. 4), inducing too great a stiffness along the principal loading direction. The global stiffness of a granular assembly does not stem only from the contact stiffness, but also from the ability of the assembly to be rearranged. This means that the local kinematic cannot be described by pairs of grains, but requires larger sets of grains to account for collective rearrangements. Thus, limiting the investigation to two-dimensional conditions, an intermediate scale, made up of a hexagonal pattern of grains, is introduced. A number of similar attempts were recently made (Agnolin et al., 2006; Agnolin and Kruyt, 2008) to propose a local kinematic description accounting for an intermediate, relevant scale.

Thereafter, a general frame $\left(\vec{x}_{1}, \vec{x}_{2}\right)$ is considered, where both $\vec{x}_{1}$ and $\vec{x}_{2}$ axes are the principal directions of the macroscopic strain tensor $\underline{\underline{\varepsilon}}$, which are first assumed not to rotate. Thus, in this frame, $\stackrel{\bar{\varepsilon}}{\varepsilon}=\left[\begin{array}{cc}\varepsilon_{1} & 0 \\ 0 & \varepsilon_{2}\end{array}\right]$. As for the microdirectional model, the $H$-microdirectional model is developed so that the incremental stress $\delta \overline{\bar{\sigma}}$ is computed for a given incremental strain $\delta \bar{\varepsilon}$.

Basically, the granular assembly is described by a distribution of regular hexagonal patterns of spherical grains with an identical radius $r_{g}$ (Fig. 6). Many other arrangements can be found in real granular assemblies. The hexagonal packing has the interest of giving rise to complex kinematic mechanisms, including local dilatant or contractant behaviors. Each hexagon is initially symmetric with respect to a given direction $\vec{n}$. At any stage of a given loading path, each hexagon is assumed to be loaded by a symmetric set of forces $\left(\vec{F}_{1}, \vec{F}_{2}\right)$ (Fig. 7), so that it continues to deform symmetrically with respect to direction $\vec{n}$. Furthermore, the deformation of any hexagon (characterized by lengths $l_{1}$ and $l_{2}$ ) is assumed to derive from the macroscopic strain on the specimen scale. Both incremental lengths $\delta l_{1}$ and $\delta l_{2}$ are related to the incremental strain tensor $\delta \bar{\varepsilon}$ as follows (Fig. 7):

$$
\begin{aligned}
& \delta l_{1}=-l_{1} \delta \varepsilon_{i j} n_{i} n_{j}=-l_{1}\left(\delta \varepsilon_{1} n_{1}{ }^{2}+\delta \varepsilon_{2} n_{2}{ }^{2}\right) \\
& \delta l_{2}=-l_{2} \delta \varepsilon_{i j} t_{i} t_{j}=-l_{2}\left(\delta \varepsilon_{1} t_{1}^{2}+\delta \varepsilon_{2} t_{2}^{2}\right)
\end{aligned}
$$


Computing the incremental stress requires determining the contact forces acting between the contacting grains. For symmetry purposes, only the contacts between grains 1 and 2, and between grains 2 and 3, are considered. The contact force applied by grain 2 to grain 1 has a normal component $N_{1}$ and a tangential component $T_{1}$. The normal force applied by grain 3 to grain 2 only has a normal component $N_{2}$, the tangential component is assumed being nil. The corresponding kinematic variables are the normal $u_{n}^{1}$ and the tangential $u_{t}^{1}$ components of the relative displacement between grains 1 and 2, and the normal component $u_{n}^{2}$ of the relative displacement between grains 2 and 3. Using notations reported in Fig. 7, it follows that:

$$
\begin{aligned}
& \delta u_{n}^{1}=\delta d_{1} \\
& \delta u_{t}^{1}=d_{1} \delta \alpha \\
& \delta u_{n}^{2}=\delta d_{2}
\end{aligned}
$$

Thus, the kinematics of each hexagon is perfectly described by the variables $d_{1}, d_{2}$, and $\alpha$, where $d_{1}$ and $d_{2}$ are branch lengths and $\alpha$ is referred to as the opening angle. The relation between these kinematic variables and the macroscopic strain (or $l_{1}$ and $l_{2}$ ) is now the subject of analysis. For this purpose, the mechanical balance of each regular hexagonal pattern is analyzed.

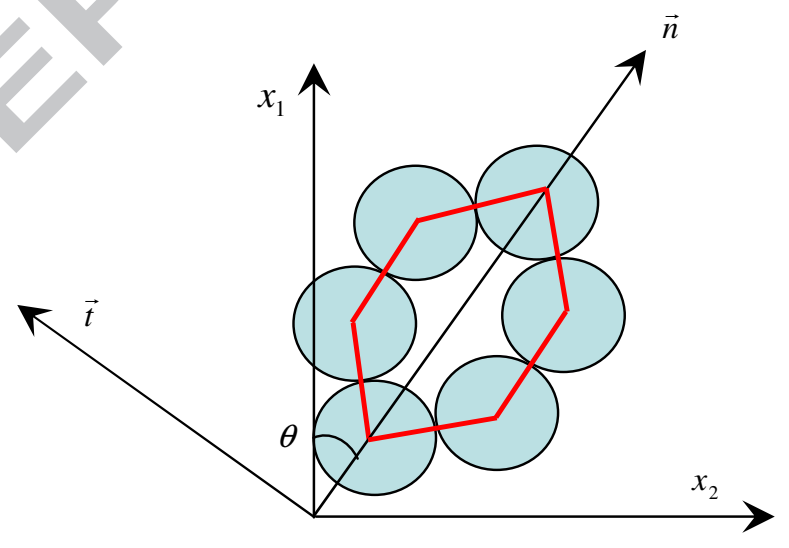

Fig. 6. Hexagonal set of contacting particles. 

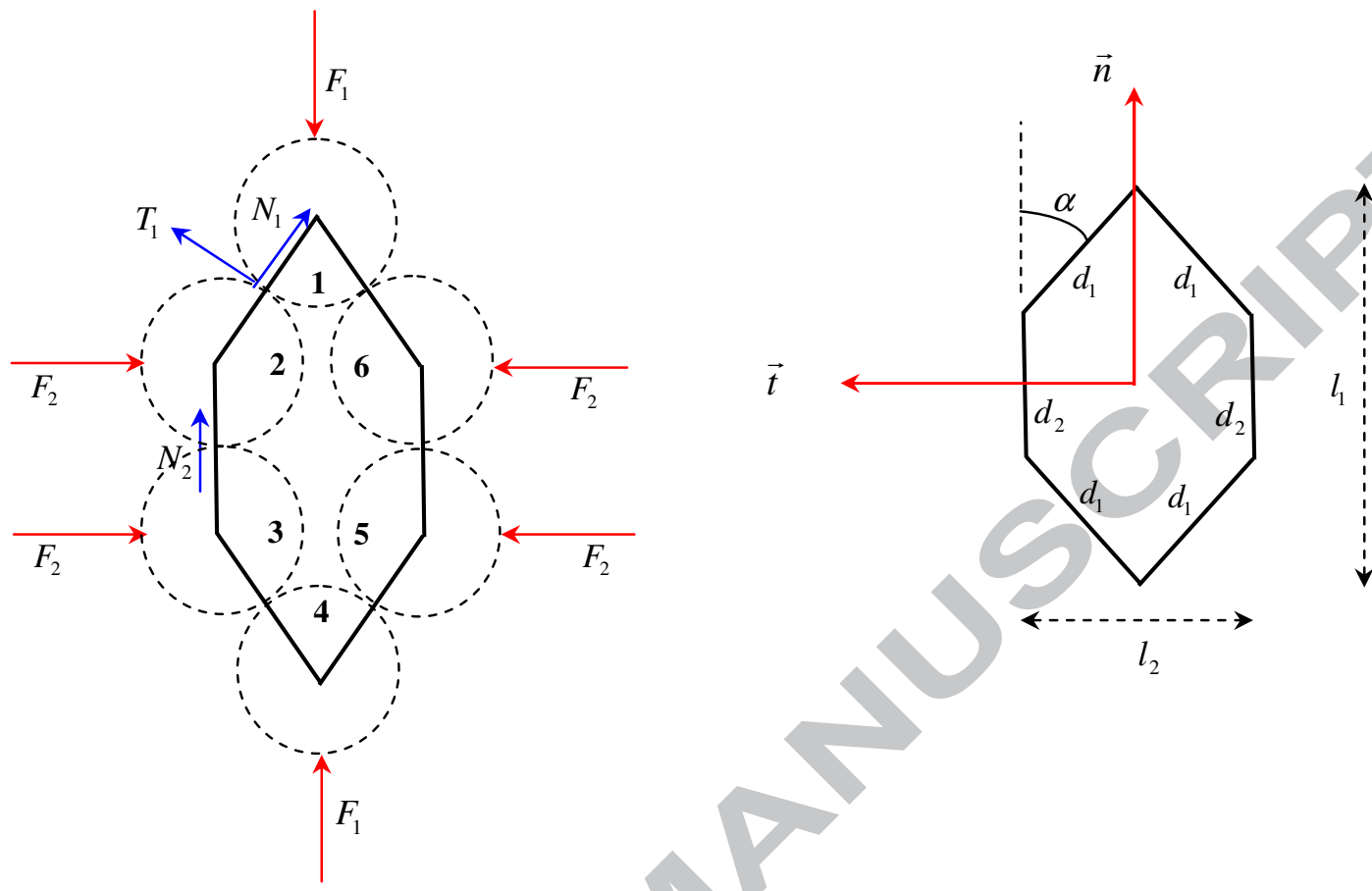

Fig. 7. Geometrical description, external forces applied to each hexagon, and contact forces.

Mechanical balance of grain 2 reads, along direction $\vec{n}$ :

$N_{2}=N_{1} \cos \alpha+T_{1} \sin \alpha$

Moreover, kinematic compatibility equations yield:

$l_{1}=d_{2}+2 d_{1} \cos \alpha$

And

$l_{2}=2 d_{1} \sin \alpha$

As for the microdirectional model (Eqs. 5a and 5b), an elastic-plastic model is introduced to relate both relative displacements and contact forces, with a Mohr-Coulomb criterion. Adopting the standard sign convention used in soil mechanics (compressive forces are positive), it follows that:

$$
\begin{aligned}
& \delta N_{1}=-k_{n} \delta d_{1} \\
& \delta N_{2}=-k_{n} \delta d_{2} \\
& \delta T_{1}=\min \left\{\left|T_{1}+k_{t} d_{1} \delta \alpha\right|, \tan \varphi_{g}\left(N_{1}+k_{n} \delta d_{1}\right)\right\} \xi-T_{1}
\end{aligned}
$$


where $\xi$ is the sign of the quantity $T_{1}+k_{t} d_{1} \delta \alpha$.

Combining Eqs. (14)-(16) expressed under an incremental formalism with constitutive Eqs. (17)-(19) yields the following algebraic system expressing the incremental changes in $d_{1}$, $d_{2}$, and $\alpha$ with respect to the incremental changes in $l_{1}$ and $l_{2}$ (see Appendix 1):

$\left[\begin{array}{ccc}2 \cos \alpha & 1 & -2 d_{1} \sin \alpha \\ 2 \sin \alpha & 0 & 2 d_{1} \cos \alpha \\ \cos \alpha+A & -1 & \frac{\left(N_{1}-B\right) \sin \alpha-T_{1} \cos \alpha}{k_{n}}\end{array}\right]\left[\begin{array}{c}\delta d_{1} \\ \delta d_{2} \\ \delta \alpha\end{array}\right]=\left[\begin{array}{c}\delta l_{1} \\ \delta l_{2} \\ C\end{array}\right]$

In the elastic regime, $A=0, B=k_{t} d_{1}$, and $C=0$, whereas in the plastic regime, $A=\xi \tan \varphi_{g} \sin \alpha, B=0$, and $C=\sin \alpha\left(\frac{\xi \tan \varphi_{g} N_{1}-T_{1}}{k_{n}}\right)$.

Averaging all incremental contact forces over the overall specimen of volume $V$ gives the macroscopic incremental stress tensor (Love formula):

$$
\bar{\sigma}=\frac{1}{V} \int \omega_{e}(\vec{n}) \overline{\bar{P}}^{-1}\left[\begin{array}{cc}
v(\vec{n}) \tilde{\sigma}_{1} & 0 \\
0 & v(\vec{n}) \tilde{\sigma}_{2}
\end{array}\right] \overline{\bar{P}} d \theta
$$

where $\overline{\bar{P}}=\left[\begin{array}{cc}\cos \theta & \sin \theta \\ -\sin \theta & \cos \theta\end{array}\right]$ is the rotation matrix from $\left(\vec{x}_{1}, \vec{x}_{2}\right)$ to $(\vec{n}, \vec{t}) . \omega_{e}(\vec{n})$ is the number of hexagons oriented along the direction $\vec{n}=\cos \theta \vec{x}_{1}+\sin \theta \vec{x}_{2} . \tilde{\sigma}_{1}$ and $\tilde{\sigma}_{2}$ are the principal components of the stress acting on the intermediate scale. $v(\vec{n})$ stands as the volume of the hexagon oriented along the direction $\vec{n}$. Using the Love formula, that applies even for a set of a few grains (De Saxce et al., 2004), it follows that:

$v(\vec{n}) \tilde{\sigma}_{1}=4 N_{1} d_{1} \cos ^{2} \alpha+4 T_{1} d_{1} \cos \alpha \sin \alpha+2 N_{2} d_{2}$

and

$v(\vec{n}) \tilde{\sigma}_{2}=4 N_{1} d_{1} \sin ^{2} \alpha-4 T_{1} d_{1} \cos \alpha \sin \alpha$ 
A major difference with respect to the microdirectional model (Nicot and Darve, 2005) is that grains appear explicitly, giving rise to both solid and void (or, more generally, internal fluid) phases. Moreover, the deformability of the specimen is mainly due to the relative sliding between particles, rather than to the normal stiffness at contacts. This is a great advantage, giving rise to a more realistic assessment of the compressibility of granular assemblies.

Besides, the void ratio $e(\vec{n})$ of each hexagonal pattern of direction $\vec{n}$ with an opening angle $\alpha$, regarded as a granular assembly, can be estimated. For this purpose, the volume $v(\vec{n})$ is assumed to be delimited by the hexagon made up of the branches relating the centers of the grains (Fig. 8). Thus, the following expression of the void ratio follows:

$$
e(\vec{n})=\frac{4 \sin \alpha(1+\cos \alpha)}{\pi}-1
$$

For a virgin specimen, before application of a loading path, the initial void ratio $e_{o}$ is also related through Eq. (24) to the initial opening angle $\alpha_{o}$. The evolution of $e_{o}$ versus $\alpha_{o}$ is given in Fig. 8. The curve has a sine-like form, passing through a maximum value $e_{o}=0.65$ at $\alpha_{o}=60 \mathrm{deg}$. Initially, the opening angle $\alpha_{o}$ is assumed to range between 30 and 60 degrees, so that the relation between $e_{o}$ and $\alpha_{o}$ is bijective. During the subsequent loading history, $\alpha_{o}$ can evolve beyond 60 degrees, thereby implying a decrease in the void ratio.

In conclusion, the $H$-microdirectional model requires three constitutive parameters to be calibrated: $k_{n}, k_{t}$, and $\varphi_{g}$. A fourth geometrical parameter, $\alpha_{o}$, can be estimated to account for the initial density of the specimen. For dense specimens, small values of $\alpha_{o}$ will be adopted, whereas larger values of $\alpha_{o}$ will be used for loose specimens.

This very restricted number of parameters is of course an advantageous feature of the model. In the following section, the ability of the model to reproduce, at least qualitatively, the main constitutive characteristics of granular assemblies along standard loading paths is investigated. Indeed, it is of great interest to examine whether such simplistic modeling, incorporating explicitly microstructural aspects with a few parameters, is sufficient to simulate some of the constitutive properties of granular assemblies. 


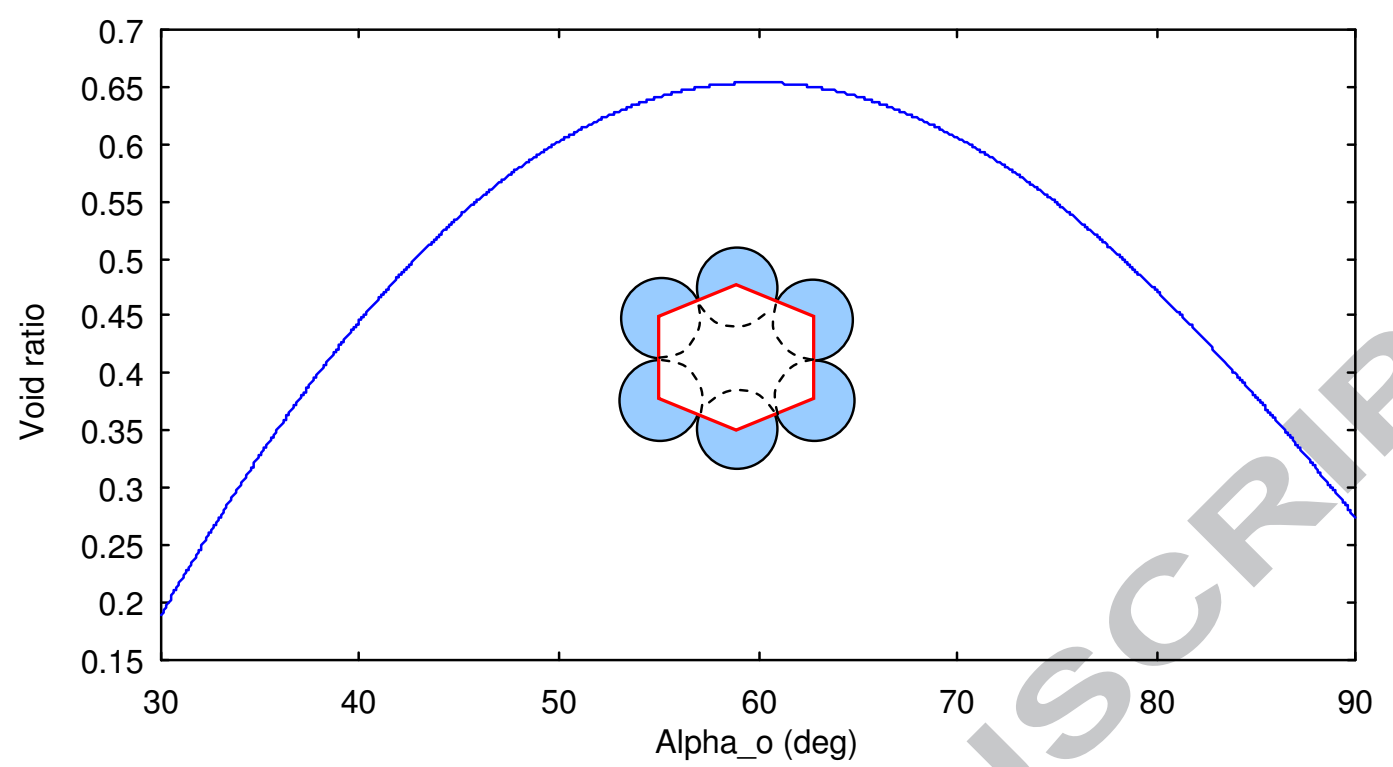

Fig. 8. Evolution of the void ratio as a function of the hexagon geometry.

\subsection{Examples of simulations along standard loading paths}

In this subsection, the simulation of the response of a dense specimen over a drained biaxial test in compression is first examined. It is worth emphasizing that the purpose is not to validate the model from a quantitative point of view, but to check its ability from a qualitative point of view.

The biaxial test is run after an initial isotropic compression at $200 \mathrm{kPa}$, using the parameters reported in Table 2.

\begin{tabular}{c|c|c|c|c|}
$\begin{array}{c}\text { Initial isotropic } \\
\text { stress }(\mathrm{kPa})\end{array}$ & $\theta_{e}(\mathrm{deg})$ & $k_{n}(\mathrm{kN} / \mathrm{m})$ & $k_{t}(\mathrm{kN} / \mathrm{m})$ & $\varphi_{g}(\mathrm{deg})$ \\
\hline 200 & 42.8 & 1,000 & 500 & 20
\end{tabular}

Table 2. Numerical simulation: constitutive parameters and initial conditions.

As seen in Figs. 9 and 10, the simulated response is qualitatively satisfying. The stress peak is obtained at a small strain (2\%), and then a softening regime is observed. The macroscopic friction angle is 31 degrees at the peak. This is a typical response for dense materials, as confirmed by the volumetric strain response shown in Fig. 10. Indeed after an initial 
contractant behavior, a dilatant regime develops. It must be noted that the softening regime obtained is constitutive, as both stress and strain are considered homogeneous. It is associated with no geometrical effect that would lead to kinematical discontinuities.

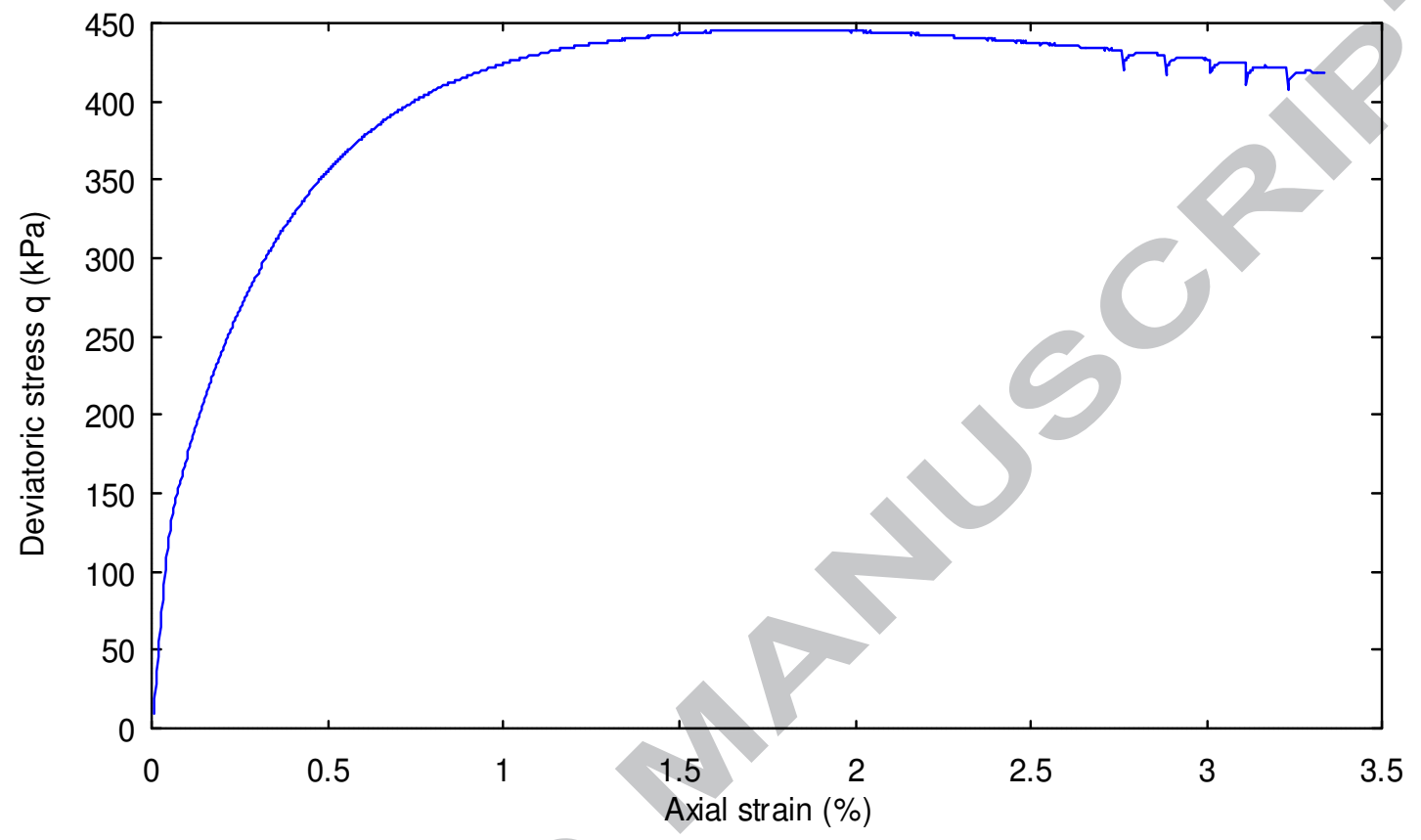

Fig. 9. Response over a drained biaxial test using the $H$-microdirectional model. Evolution of the deviatoric stress versus the axial strain.

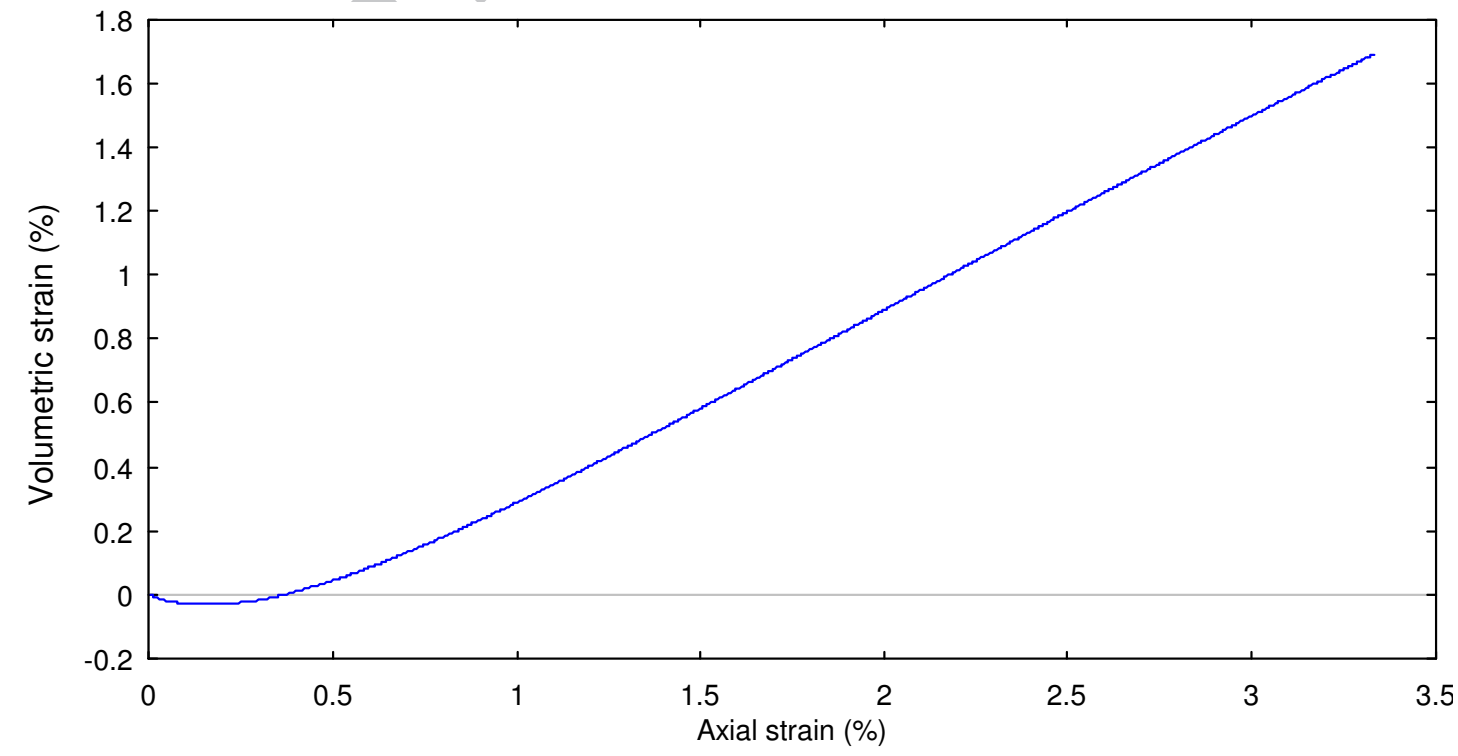

Fig. 10. Response over a drained biaxial test using the $H$-microdirectional model. Evolution of the volumetric strain versus the axial strain. 
The evolution of the microstructure over the loading path can be analyzed from the distribution of the hexagons' opening angle $\alpha$. Initially, the distribution of angle $\alpha$ along each direction $\vec{n}$ is isotropic. As the hexagons oriented along the different directions may behave differently, the distribution progressively develops anisotropy. Figure 11 shows the distribution of angle $\alpha$ over each direction $\vec{n}$. The initial isotropy is represented by the horizontal straight line (isotropic distribution). After $2 \%$ of axial strain, the distribution of angle $\alpha$ departs from the isotropic distribution. As expected, for hexagons oriented along the axial direction ( $\theta$ close to $0(\pi) \mathrm{rad}), \alpha$ has increased, indicating that hexagons have opened along this direction. In contrast with the microdirectional model, the deformability along the axial direction does not stem from the normal rigidity between adjoining spheres, but from the rearrangement of particles mobilizing essentially sliding mechanisms. On the other hand, hexagons oriented along the radial direction have closed, with a reduction of angle $\alpha$. Indeed, radial directions are extension directions. Eventually, opening may occur between those particles for larger strains.

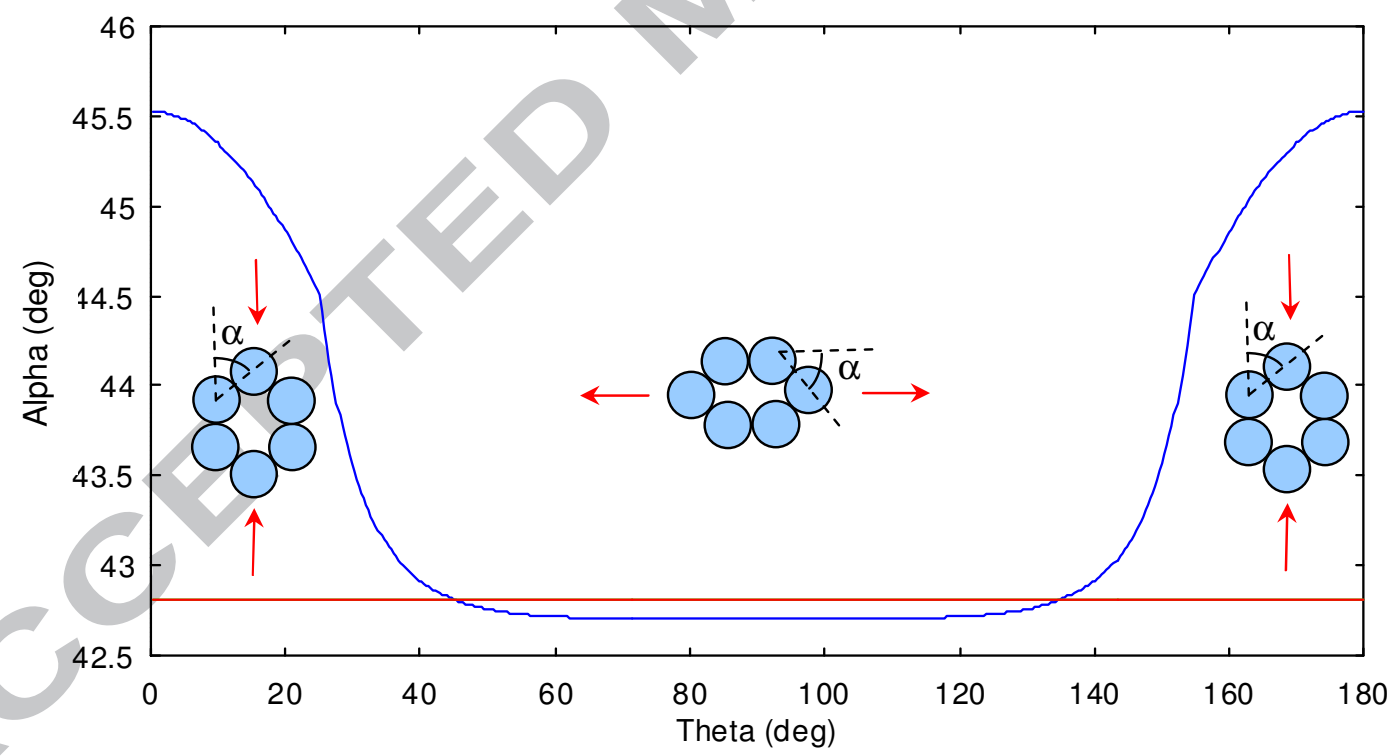

Fig. 11. Distribution of the opening angle with respect to the orientation of the hexagon at $2 \%$ of axial strain. Arrows indicate whether the hexagon is stretched (angle $\alpha$ deceases) or compressed (angle $\alpha$ increases). 


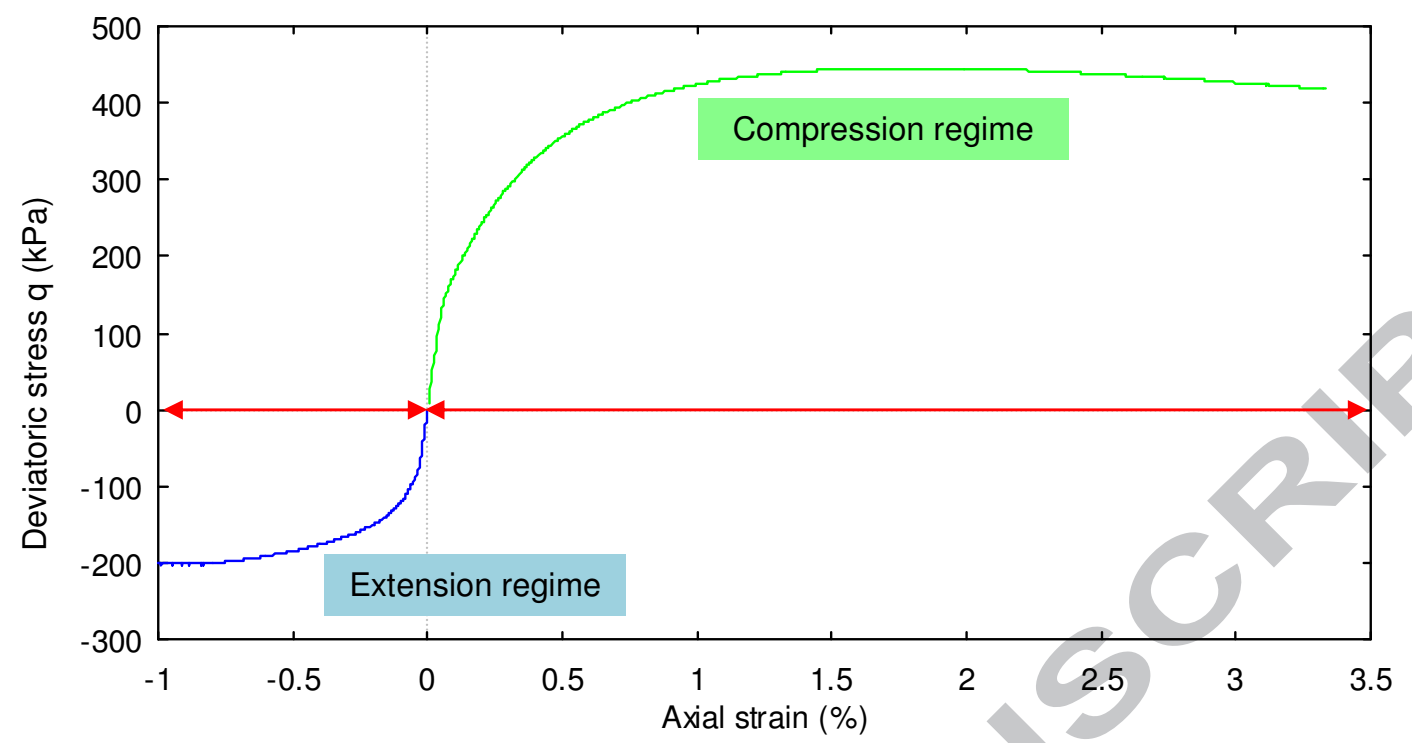

Fig. 12. Response over a drained biaxial test using the $H$-microdirectional model, in both extension and compression. Evolution of the deviatoric stress against the axial strain.

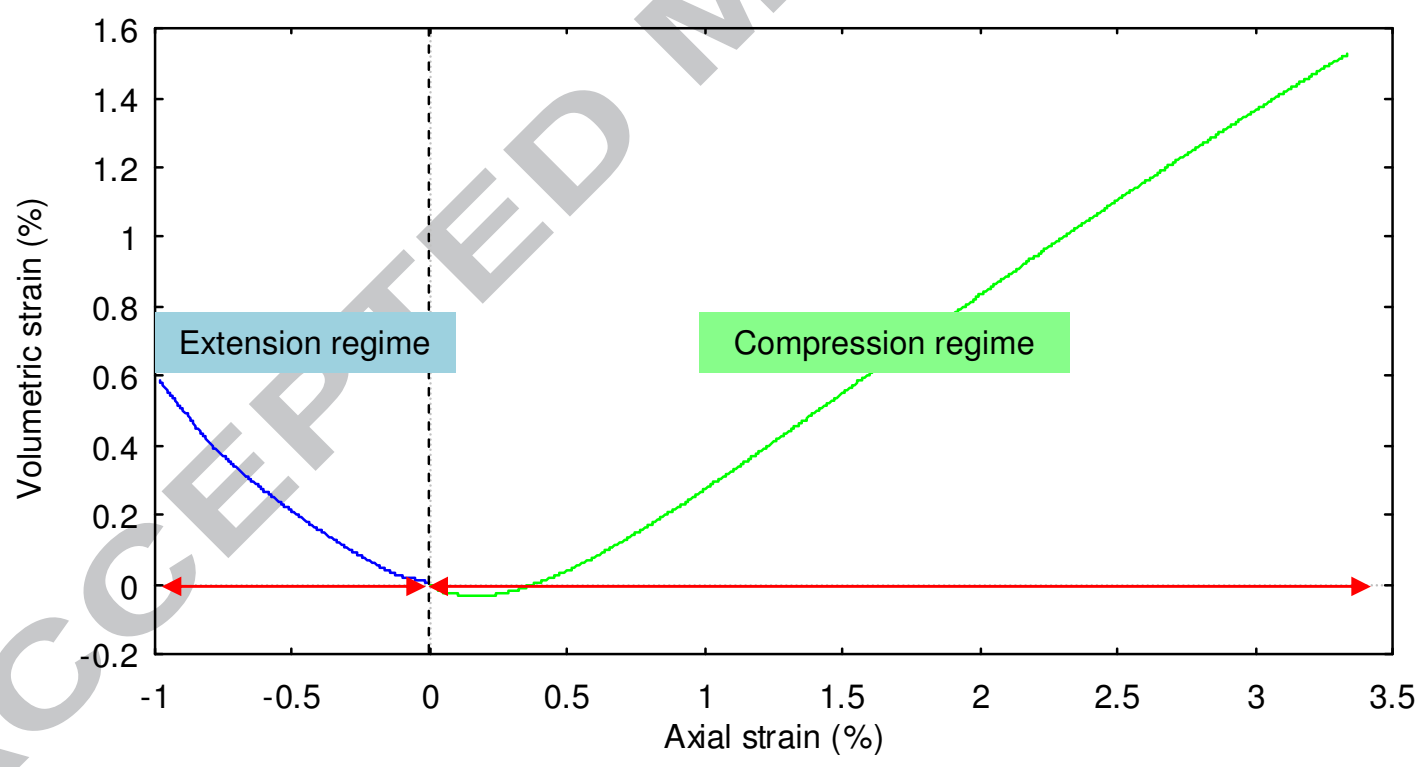

Fig. 13. Response over a drained biaxial test using the $H$-microdirectional model, in both extension and compression. Evolution of the volumetric strain against the axial strain.

To have a more complete insight on the capabilities of the model, a drained biaxial test in extension was also simulated, using the same parameters as preciously. The results are shown in Figs. 12 and 13, where the change in both the deviatoric stress and the volumetric strain is 
given in terms of the axial strain. Both the compression and the extension paths are displayed. As expected, the deviatoric stress for the extension path decreases, following a quasi linear response along a straight line which is approximately aligned with the initial part of the curve for the compression path. Then, a plateau is reached, with no softening effect, where the deviatoric stress equals the opposite of the confining pressure $(200 \mathrm{kPa})$. The volumetric strain curve displays a dilatant behaviour, with a dilatancy angle higher than that observed during the compressive biaxial test.

To go further, the same biaxial tests were run at different initial confining pressures $\sigma_{2}(100$ $\mathrm{kPa}, 200 \mathrm{kPa}, 300 \mathrm{kPa}$, and $400 \mathrm{kPa}$ ). The same parameters as those reported in Table 2 were used. For each simulation, the deviatoric ratio $\frac{q}{p}=2 \frac{\sigma_{1}-\sigma_{2}}{\sigma_{1}+\sigma_{2}}$ is plotted against the axial strain. In two-dimensional conditions, the deviatoric ratio can be related to the mobilized macroscopic friction angle $\varphi_{m}$ as follows:

$$
\frac{q}{p}=2 \sin \varphi_{m}
$$

As observed in Fig. 14, all the curves converge toward more or less the same limit value, close to 1. As seen in Fig. 9, the deviatoric stress curve reaches a residual plateau after the peak (softening regime). Therefore, Fig. 14 shows that the macroscopic friction angle at the plateau slightly depends on the initial confining pressure. According to Eq. (25), an asymptotical value of 30 degrees is reached. This is in line with the results obtained from biaxial or drained triaxial experimental tests (Biarez and Hicher, 1994). This is also corroborated from numerical simulations using a discrete element method (see for instance Bardet and Proubet, 1989; Bardet, 1994). 


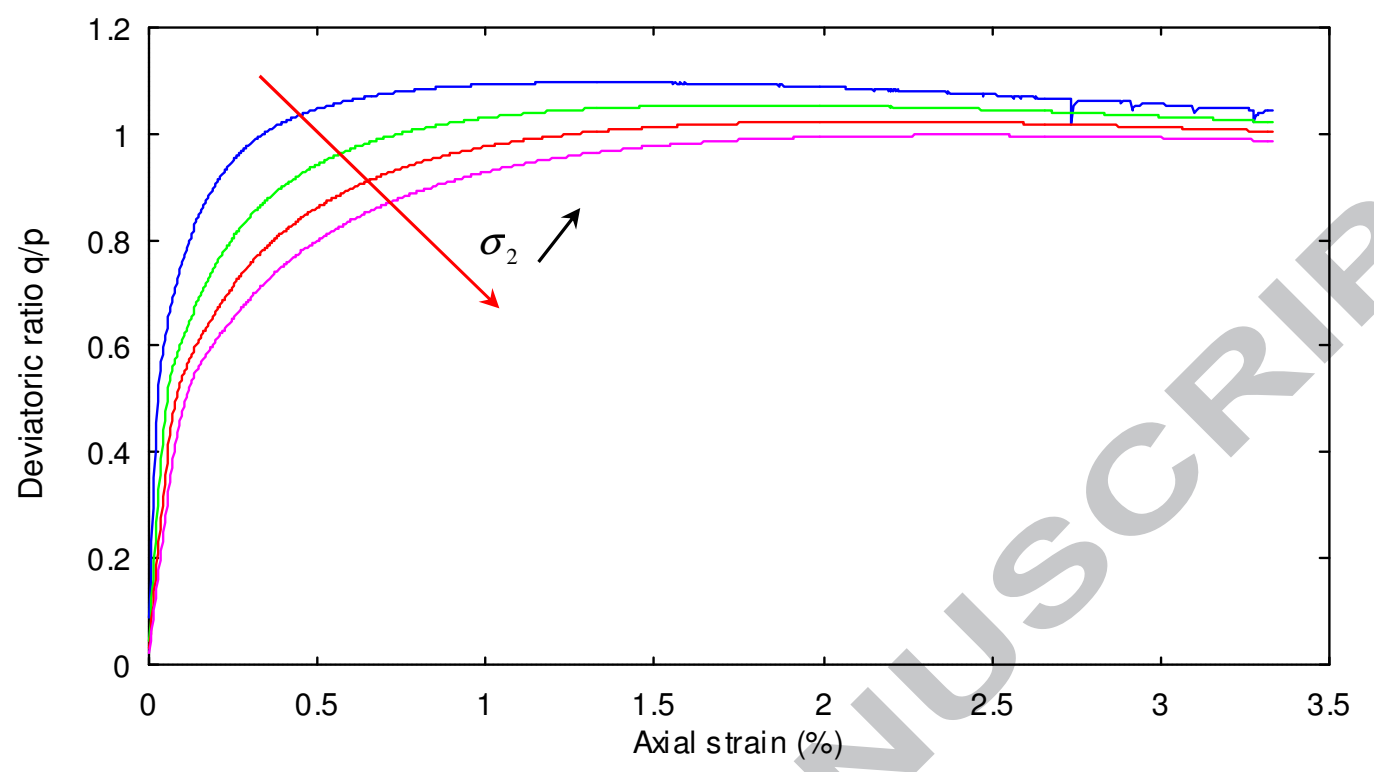

Fig. 14. Evolution of the deviatoric ratio versus the axial strain at different initial confining pressures.

Finally, proportional strain paths are considered. After a first isotropic confining loading, a constant axial strain rate $\delta \varepsilon_{1}$ is imposed, and the proportional condition $\delta \varepsilon_{2}=R \delta \varepsilon_{1}$ is prescribed. This is a generalization of the well-known undrained (isochoric) biaxial test, corresponding to the value $R=-1$, where the volume of the specimen is imposed to remain constant. This set of loading paths is advantageous to the extent that any direction in the incremental strain space can be explored.

The response is investigated by analyzing how the conjugate stress variable $\sigma_{1}+R \sigma_{2}$ evolves in relation to the axial strain $\varepsilon_{1}$. For this purpose, the parameters reported in Table 2 were used. As observed in Fig. 15, the curve of $\sigma_{1}+R \sigma_{2}$ passes through a peak for $R$ values lower than the critical value $\bar{R}=-1.2$. For sufficiently low $R$ values, stresses eventually vanish, leading to the liquefaction of the specimen. This is a generalization of what is observed along isochoric biaxial or triaxial paths, where a liquefaction mechanism occurs for loose specimens. Thus, investigating proportional strain paths makes it possible to check whether a certain failure mode may occur even for dense specimens. 


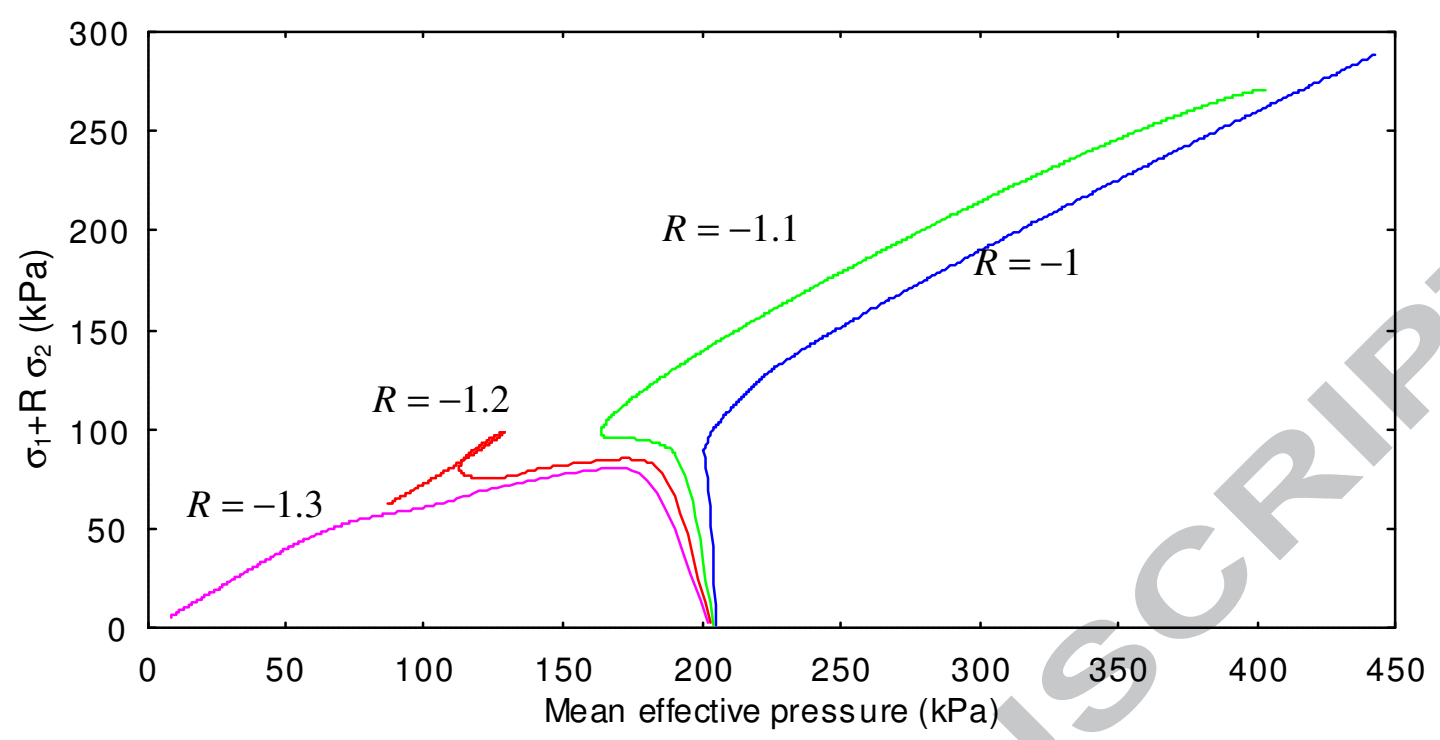

Fig. 15. Response over a proportional strain loading path using the $H$-microdirectional model.

Thus, for $R$ values lower than $\bar{R}=-1.2$, limit states exist within the stress space before reaching Mohr Coulomb line. The existence of such limit states was broadly discussed in the past (see for instance Darve et al., 2004) As recently shown by Nicot et al. (2009) and Prunier et al. (2009), the second-order work takes negative or nil values when the limit state is reached. The second-order work corresponds to the quadratic form associated with the symmetric part $\overline{\bar{K}}^{s}$ of the constitutive tensor $\overline{\bar{K}}$ relating both incremental strain and stress vectors. Thus, the vanishing of the second-order work also means that the matrix $\overline{\bar{K}}^{s}$ is singular. According to the theoretical background (Nova, 1994; Darve et al., 2004; Nicot and Darve, 2007c), the specimen's diffuse failure (with no localization pattern in the kinematics field, as shown in experimental tests; Daouadji et al., 2010) is expected if any additional deviatoric load is applied at the peak or along the descending branch.

The ability of the microdirectional model to give rise to diffuse failure has been discussed (Nicot and Darve, 2006). The above results show that this feature remains with the $H$ microdirectional model. This result confirms the relevance of such micromechanical approaches to investigate failure states. Furthermore, such approaches allow investigation of the microstructural origin of these macroscopic failure features. In particular, the directional nature of the model, giving rise to a distribution of oriented grain mesoscopic assemblies behaving in different mechanical regimes (some hexagons contract, others dilate, with 
contacts in an elastic or a plastic regime), should likely play a fundamental role in the emergence of such properties. This issue will be considered in a forthcoming paper. 


\section{CONCLUDING REMARKS}

The main purpose of this paper was to propose some elements of answer to the question: how to build a macroscopic constitutive relation for granular media by taking into account the local interaction law between grains as properly as possible?

Some aspects of the answer have already emerged from the experience capitalized with molecular dynamics modelling. Indeed, it is widely observed now that the extreme complexity of the macroscopic behaviour of granular media is well simulated in molecular dynamics methods by a very simple local elastic-plastic law (with two elastic stiffnesses and one friction angle), but a high number of grains in interaction. This is why, in the scheme in Fig. 1, the local behaviour was chosen as simple as possible, as in the first model proposed by the authors (Nicot and Darve, 2005), and as in discrete element methods.

Because of the success of these discrete methods in simulating this complex macroscopic behaviour, and also because the stress homogenization using Love's relation (Fig. 1) is well established and numerically verified, the choice has been made to enrich the geometrical and kinematical description of a granular medium by introducing an intermediate granular assembly at a mesoscopic scale. This is the so-called granular hexagon, giving rise to the $\mathrm{H}$ microdirectional model.

The first results presented in this paper are promising: the quality of the macroscopic description of the mechanical behaviour was improved with respect to the first model. Quantitative agreement with experimental lab test results can now be expected (see Figs. 9, $10,12,13,14$ and 15), while the first model had shown its capacity to describe qualitatively the main features of granular behaviour, like its full incremental non-linearity (Darve and Nicot, 2005a), the singularity of the flow rule with a vertex effect (Darve and Nicot, 2005b) and the existence of a bifurcation domain with instability cones (Nicot and Darve, 2006). The predictive capacity of this new micromechanical model will be carefully investigated and discussed in forthcoming papers.

Finally the interest of a micromechanical description versus a phenomenological one is to open the possibility of investigating at the granular micro-scale the origins of some macroscopic mechanical properties. This powerful way of understanding granular behaviour will be also explored in the future. 


\section{APPENDIX 1}

Differentiation of kinematic compatibility equations (15) and (16) yields:

$2 \cos \alpha \delta d_{1}+\delta d_{2}-2 d_{1} \sin \alpha \delta \alpha=\delta l_{1}$

(A1)

and

$2 \sin \alpha \delta d_{1}+2 d_{1} \cos \alpha \delta \alpha=\delta l_{2}$

Differentiation of Eq. (14) gives:

$\delta N_{2}=\delta N_{1} \cos \alpha-N_{1} \sin \alpha \delta \alpha+\delta T_{1} \sin \alpha+T_{1} \cos \alpha \delta \alpha$

With the help of constitutive relations (17) and (18), Eq. (A1) becomes:

$k_{n} \delta d_{1} \cos \alpha-k_{n} \delta d_{2}+\left(N_{1} \sin \alpha-T_{1} \cos \alpha\right) \delta \alpha=\delta T_{1} \sin \alpha$

In elastic regime, $\delta T_{1}=k_{t} d_{1} \delta \alpha$, and Eq. (A.4) reads:

$k_{n} \delta d_{1} \cos \alpha-k_{n} \delta d_{2}+\left(\left(N_{1}-k_{t} d_{1}\right) \sin \alpha-T_{1} \cos \alpha\right) \delta \alpha=0$

In plastic regime, $\delta T_{1}=\tan \varphi_{g}\left(N_{1}-k_{n} \delta d_{1}\right) \xi-T_{1}$, and Eq. (A.4) reads:

$k_{n} \delta d_{1}\left(\cos \alpha+\tan \varphi_{g} \xi \sin \alpha\right)-k_{n} \delta d_{2}+\left(T_{1} \cos \alpha-N_{1} \sin \alpha\right) \delta \alpha=\left(\xi \tan \varphi_{g} N_{1}-T_{1}\right) \sin \alpha$

where $\xi$ is the sign of the quantity $T_{1}+k_{t} d_{1} \delta \alpha$.

Equations (A1), (A2), (A5) and (A6) can be merged into the following algebraic system expressing the incremental changes in $d_{1}, d_{2}$ and $\alpha$ with respect to the incremental changes in $l_{1}$ and $l_{2}$ :

$\left[\begin{array}{ccc}2 \cos \alpha & 1 & -2 d_{1} \sin \alpha \\ 2 \sin \alpha & 0 & 2 d_{1} \cos \alpha \\ \cos \alpha+A & -1 & \frac{\left(N_{1}-B\right) \sin \alpha-T_{1} \cos \alpha}{k_{n}}\end{array}\right]\left[\begin{array}{c}\delta d_{1} \\ \delta d_{2} \\ \delta \alpha\end{array}\right]=\left[\begin{array}{c}\delta l_{1} \\ \delta l_{2} \\ C\end{array}\right]$ 
where $A=0, B=k_{t} d_{1}$ and $C=0$ in the elastic regime, and $A=\xi \tan \varphi_{g} \sin \alpha, B=0$ and $C=\sin \alpha\left(\frac{\xi \tan \varphi_{g} N_{1}-T_{1}}{k_{n}}\right)$ in the plastic regime.

\section{ACKNOWLEDGMENTS}

The French Federative Research Structure MeGe (Multiscale and multiphysical coupling in geo-environmental mechanics) is gratefully acknowledged by the authors.

\section{REFERENCES}

Agnolin, I., and Kruyt, N.P. (2008): On the elastic moduli of two-dimensional assemblies of disks, relevance and modeling of fluctuations in particle displacements and rotations. Computers and Mathematics with Applications, Vol. 55, pp. 245-256.

Agnolin, I., and Roux, J.N. (2008): On the elastic moduli of three-dimensional assemblies of spheres: Characterization and modeling of fluctuations in the particle displacement and rotation. International Journal of Solids and Structures, Vol. 45(3-4), pp. 1101-1123.

Agnolin, I., Jenkins, J.T., and La Ragione, L. (2006): A continuum theory for a random array of identical elastic frictional disks. Mechanics of Materials, Vol. 38, Issues 8-10, pp. 687701.

Bardet, J.P., and Proubet, J. (1989): Application of micro-mechanics to incrementally nonlinear constitutive equations for granular media. In Powders and Grains, Edited by J. Biarez and R. Gourvès, pp. 265-273.

Bardet, J.P. (1994): Numerical simulations of the incremental responses of idealized granular materials. Int. Journal of Plasticity, Vol. 10, $\mathrm{n}^{\circ}$ 8, pp. 879-908.

Bazant, Z.P. (1978): Endochronic inelasticity and incremental plasticity. International Journal of Solids and Structures, Vol. 14, pp. 691-714.

Biarez, J., and Hicher, P.Y. (1994): Elementary mechanics of soil behaviour, saturated remoulded soils. Balkema.

Cambou, B., Chaze, M., and Dedecker, F. (2000): Change of scale in granular materials. Eur. J. Mech. A/Solids, vol. 19, Elsevier Ed., pp.999-1014. 
Cambou, B., Dubujet, P., Emeriault, F., and Sidoroff, F. (1995): Homogenization for granular materials. European Journal of Mechanics, A/Solids, Vol. 14, n 2, pp. 255-276.

Castro, G. (1969): Liquefaction of sands. Harvard Soil Mechanics series, Vol. 81, Harvard University.

Chang, C.S., and Hicher, P.Y. (2005): An elasto-plastic model for granular materials with microstructural consideration. Int. J. of Solids and Structures, Vol. 42(14), pp. 4258-4277.

Christoffersen, J., Mehrabadi, M.M., and Nemat-Nasser, S. (1981): A micro-mechanical description of granular material behavior. Journal of Applied Mechanics, Vol. 48, pp. 339344.

Chu, J., Leroueil, S., and Leong, W.K. (2003): Unstable behavior of sand and its implication for slope instability. Can. Geotech. Journal, Vol. 40, pp. 873-885.

Cundall, P.A. and Roger, D.H. (1992): Numerical modelling of discontinua, Engineering computations, Vol. 9, pp. 101-113.

Daouadji A., AlGali H., Darve F., Zeghloul A. (2010): Instability in granular materials: an experimental evidence of diffuse mode of failure for loose sands, Journal of Engineering Mechanics, Vol. 136 (5), pp. 575-588.

Darve, F. (1990): The expression of rheological laws in incremental form and the main classes of constitutive equations. In Geomaterials constitutive equations and modelling, F. Darve ed., Taylor and Francis Books, pp. 123-148.

Darve, F., and Vardoulakis, I. (2005): Instabilities and degradations in geomaterials. Darve and Vardoulakis Eds., CISM course, Springer Publ.

Darve, F., Flavigny, E., and Meghachou, M. (1995): Yield surfaces and principle of superposition revisited by incrementally non-linear constitutive relations. Int. J. Plasticity, Vol. 11, n 8 , pp. 927-948.

Darve, F., Servant, G., Laouafa, F., and Khoa H.D.V. (2004): Failure in geomaterials, continuous and discrete analyses. Comp. Methods Appl. Mech. Engrg., Vol. 193, pp. 30573085.

Darve, F., and Nicot, F. (2005a): On incremental non linearity in granular media: phenomenological and multi-scale views (Part I). Int. J. Num. Anal. Methods in Geomechanics. Vol. 29, pp. 1387-1409.

Darve, F., and Nicot, F. (2005b): On flow rule in granular media, phenomenological and multi-scale views (Part II). Int. J. Numerical Analytical Methods in Geomech, Vol. 29, pp. 1411-1432. 
De Saxcé, G., Fortin, J., and Millet, O. (2004): About the numerical simulation of the dynamics of granular media and the definition of the mean stress tensor. Mechanics of Materials, Vol. 36(12), pp. 1175-1184.

Drescher, A., and de Josselin de Jong, G. (1972): Photoelastic verification of a mechanical model for the flow of a granular material. Journal of the Mechanics and Physics of Solids, Vol. 20(5), pp. 337-340.

Hill, R. (1967): On the classical constitutive relations for elastic-plastic solids. In Recent progress in applied mechanics, Folke Odqvist Volume, B. Broberg, J. Hult and F. Niordson Eds., Almqvist and Wiksell, pp. 241-249.

Horne, M.R. (1965): The behaviour of an assembly of rotund, rigid cohesionless particles - I, II. Proc. Royal Society London, Vol. 286, pp. 62-97.

Kolymbas, D. (1991): An outline of hypoplasticity. Archive of Applied Mechanics, Vol. 61, pp. 143-151.

Kolymbas, D. (1999): Introduction to hypoplasticity. Balkema Publisher, 104 p.

Kruyt, N.P., and Rothenburg, L. (2002): Micromechanical bounds for the effective elastic moduli of granular materials. International Journal of Solids and Structures, Vol. 39(2), pp. 311-324.

Lade, P.V., and Pradel, D. (1990): Instability and flow of granular materials, I: Experimental observations. ASCE J. Engr. Mech., Vol. 116, pp. 2532-2550.

Lade, P.V. (1992): Static instability and liquefaction of loose fine sandy slopes. J. Geotech. Engin. ASCE., Vol. 118, pp. 51-71.

Love, A.E.H. (1927): A treatise of mathematical theory of elasticity. Cambridge University Press, Cambridge.

Mehrabadi, M.M., Oda, M., and Nemat-Nasser, S. (1982) : On statistical description of stress and fabric in granular materials. Int. J. Num. Anal. Meth. Geomech., Vol. 6, pp. 95-108.

Nemat-Nasser, S. (2000): A micromechanically-based constitutive model for frictional deformation of granular materials. Journal of the Mechanics and Physics of Solids, Vol. $48, n^{\circ} 6-7$, pp. 1541-1563.

Nemat-Nasser, S., and Mehrabadi, M.M. (1984): Micromechanically based rate constitutive descriptions for granular materials. In Mechanics of engineering materials, Proc. Int. Conf. Constitutive Law for Eng. Mat. Theory and application, C.S. Desai and R.H. Gallagher Eds., John Wiley \& Sons, New York.

Nicot, F. (2003): Constitutive modelling of a snowcover with a change in scale. European Journal of Mechanics (A / Solids), Vol. 22-3, pp. 325-340. 
Nicot, F. (2004): From a constitutive modelling of a snowcover to the design of flexible structures. Part I, Mechanical modelling. International Journal of Solids and Structures. Vol. 41/11-12, pp. 3317-3337.

Nicot, F., and Darve, F. (2005): A multiscale approach to granular materials. Mechanics of Materials, Vol. 37 (9), pp. 980-1006.

Nicot, F., and Darve, F. (2006): Micro-mechanical investigation of material instability in granular assemblies. Int. J. of Solids and Structures, Vol. 43, pp. 3569-3595.

Nicot, F., and Darve, F. (2007a): Basic features of plastic strains: from micro-mechanics to incrementally nonlinear models. Int. Journal of Plasticity, Vol. 23, pp. 1555-1588.

Nicot, F., and Darve, F. (2007b): Micro-mechanical bases of some salient constitutive features of granular materials. Int. J. of Solids and Structures, Vol. 44, pp. 7420-7443.

Nicot, F., and Darve, F. (2007c): A micro-mechanical investigation of bifurcation in granular materials. Int. J. of Solids and Structures, Vol. 44, pp. 6630-6652.

Nicot, F., Darve, F., and Khoa, H.D.V. (2007): Bifurcation and second-order work in geomaterials. Int. J. Num. Anal. Methods in Geomechanics, Vol. 31, pp. 1007-1032.

Nicot, F., Sibille, L., and Darve, F. (2009): Bifurcation in granular materials: an attempt at a unified framework. Int. J. of Solids and Structures, Vol. 46, pp. 3938-3947.

Oda, M. (1972): The mechanism of fabric changes during compressional deformation of sand. Soils and Foundations, Vol. 12, pp. 1-23.

Pastor, M., Zienkiewicz, O.C., and Chan, A.H.C. (1990): Generalized plasticity and the modeling on soil behavior. Int. Journal for Numerical and Analytical Methods in Geomechanics, Vol. 14, pp. 151-190.

Radjai, F., Roux, S., and Moreau, J.J. (1999): Contact forces in a granular packing. Chaos, Vol. 9, n' 3, pp. 544-550.

Rice, J.R. (1970): On the structure of stress-strain relations for time-dependent plastic deformation in metals. Journal of Applied Mechanics, Vol. 37, pp. 728-737.

Rice, J.R. (1975): Continuum mechanics and thermodynamics of plasticity in relation to microscale deformation mechanisms. Constitutive equations in plasticity, A.S. Argon Ed., MIT Press, Cambridge, pp. 23-79.

Taylor, G.I. (1934): The mechanism of plastic deformation of crystals - I, theoretical. Proc. Of the Royal Society of London, A, Vol. 145, pp. 362-387.

Taylor, G.I. (1938): Plastic strains in metals. J. Inst. Metals, Vol. 62, pp. 307-325.

Tordesillas, A. (2007): Force chain buckling, unjamming transitions and shear banding in dense granular assemblies. Phil. Mag. Vol. 87(32), pp. 4987-5016. 
Tordesillas, A., and Muthuswamy, M. (2009): On the modeling of confined buckling of force chains. Journal of the Mechanics and Physics of Solids, Volume 57(4), pp. 706-727.

Tordesillas, A., Walker, D.M., and Lin, Q. (2010): Force cycles and force chains. Physical Review E, Vol. 81, 011302.

Valentino, R, Barla, G., and Montrasio, L. (2008): Experimental analysis and micromechanical modelling of dry granular flow and impacts in laboratory flume tests. Rock Mech. Rock Eng., Vol. 41(1), pp. 153-177.

Walker, D.M., and Tordesillas, A.(2010): Topological evolution in dense granular materials: a complex networks perspective. Int. J. of Solids and Structures, Vol. 47, pp. 624-639.

Zienkiewicz, O.C., and Mroz, Z. (1984): Generalized plasticity formulation and applications to geomechanics. Mechanics of Engineering Materials, C.S. Desai and R.H. Gallagher Eds., Wiley, 655-679. 